\title{
ФЛЮИДНЫЙ РЕЖИМ ПРИ ФОРМИРОВАНИИ РЕДКОЗЕМЕЛЬНОЙ МИНЕРАЛИЗАЦИИ В МЕТАСОМАТИТАХ И КВАРЦОЛИТАХ ЗАПАДНЫХ КЕЙВ, КОЛЬСКИЙ ПОЛУОСТРОВ
}

\section{Зозуля Д.Р., Лялина Л.М., Савченко Е.Э.}

Геологический институт КНЦ РАН, Anamиты, zozulya@geoksc.apatity.ru

Породы Кейвской щелочногранитной провинции Балтийского щита занимают площадь по-

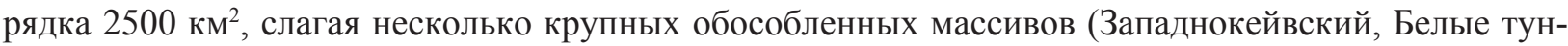
дры, Понойский, Стрельнинский и др.) и многочисленные мелкие штоки, жилы и дайки. В ходе комплексного изучения редкометальных ( $\mathrm{Zr}, \mathrm{REE}, \mathrm{Y}, \mathrm{Nb}, \mathrm{Th}$ ) проявлений, связанных со щелочными гранитами, установлено три генетических типа рудных (редкометальных) объектов: 1) автометасоматиты (минерализованные граниты), 2) метасоматиты (альбититы, микроклиниты, апобазитовые метасоматиты), 3) пегматиты и кварцолиты. В данной работе изучены геохимические особенности (главным образом REE) поздне- и постмагматических образований (апобазитовые метасоматиты Ельозерского месторождения и кварцолиты Ровозерского проявления) и их редкоземельная минерализация.

Ельозерское редкометальное месторождение приурочено к линейной тектонической зоне между Кейвским и Центральнокольским террейнами Балтийского щита. Зона простирается на 12 км в ЮВ-С3 направлении и имеет ширину от 200 до 1500 м. Месторождение генетически связано с позднеархейскими Кейвскими щелочными гранитами и состоит из нескольких сотен апогранитных и аплитовых жил протяженностью 50-500 м и мощностью 3-50 м во вмещающих габброанортозитах, амфиболитах и гнейсах. Выделены две группы рудных тел, различающихся по происхождению и минеральным парагенезисам: 1) минерализованные (циркон, торит) кварц-альбитовые с эгирином жилы (автометасоматиты); 2) высокоминерализованные (минералы Zr, REE, Nb, Th) кварц-эпидот-лепидомелановые с Сa-Na амфиболом жилы и тела неправильной формы (апобазитовые метасоматиты на контакте гранитов и основных пород). Формирование автометасоматитов соответствует поздне- и постмагматическому этапу эволюции рудомагматической системы. Содержание Zr в метасоматитах этого типа достигает 19000-38000 ppm. Апобазитовые метасоматиты формировались в наиболее низкотемпературных гидротермальных условиях и характеризуются высокими содержаниями таких редких элементов как REE (до 85000 ppm), Y (до 42000 ppm), Nb (до 62000 ppm), Zr (до 67000 ppm), Th (до 17000 ppm). Распределение REE в апобазитовых метасоматитах имеет V-образную форму (рис. 1), что характерно для пород, испытавших гидротермальную переработку фторсодержащими растворами $[2,5,9]$.

В апобазитовых метасоматитах установлены следующие редкометальные минералы: рудообразующие (главные) фазы (от ранних к поздним: торит, циркон, фергусонит-(Y), самарскит-(Y), чевкинит-(Се), алланит-(Се)) и второстепенные (и акцессорные) фазы (монацит-(Се), эшинит-(Y),
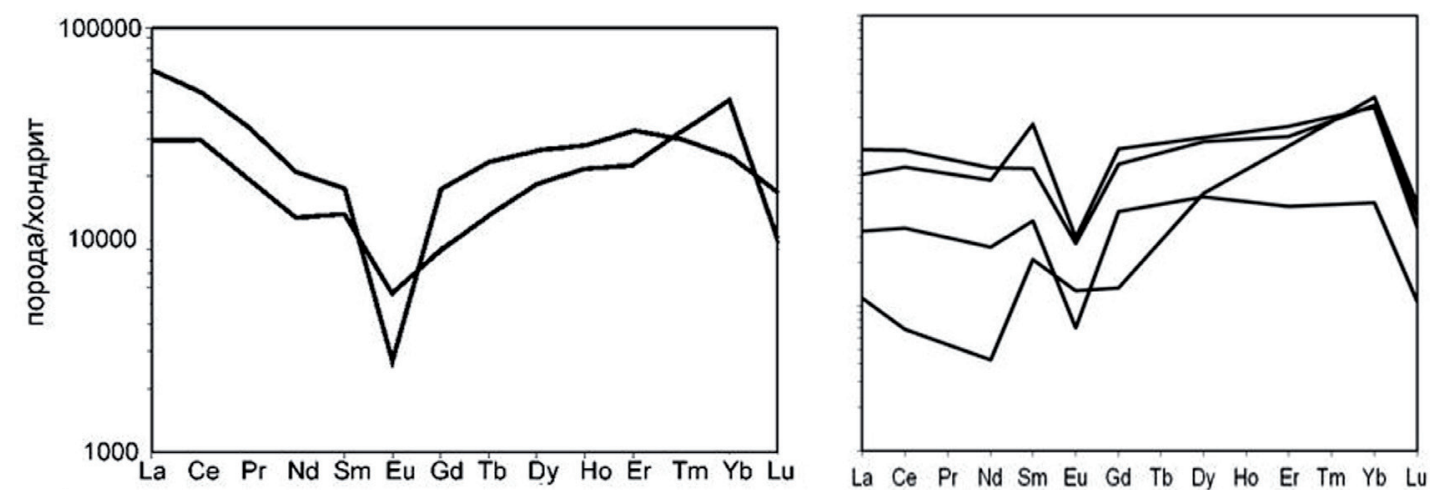

(a)

Рис. 1. Хондрит-нормализованное распределение REE в апобазитовых метасоматитах Ельозерского месторождения (а) и кварцолитах Ровозерского проявления (б). 

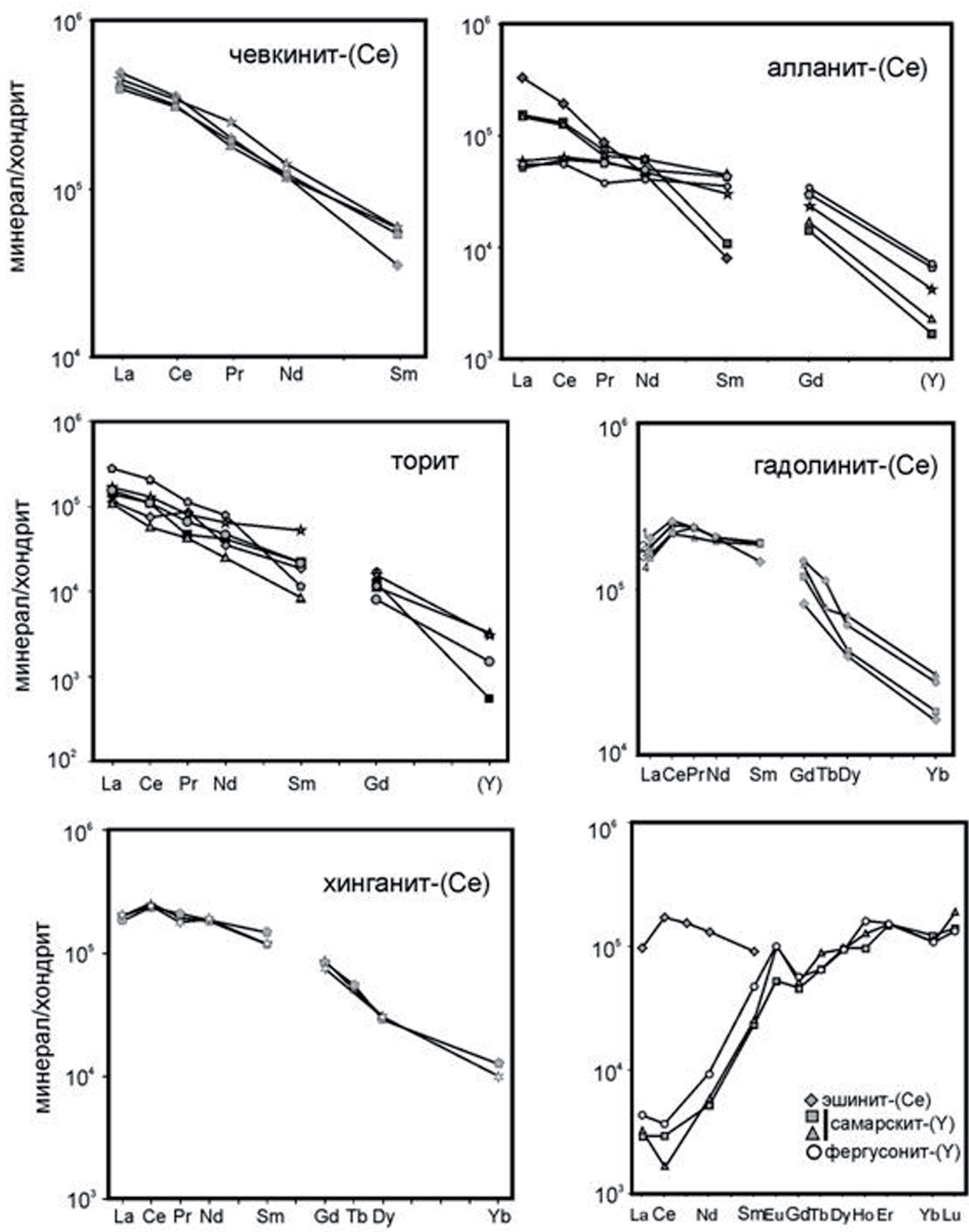

Рис. 2. Хондрит-нормализованное распределение REE в минералах Ельозерского месторождения.

эшинит-(Ce), пирохлор, Nb-содержащий рутил, давидит-(La), уранинит, торогумит, гадолинит$(\mathrm{Ce})$, хинганит-(Се), фторбритолит-(Се), даналит, бастнезит-(Се), гидроксилбастнезит-(Се)). LREE накапливаются преимущественно в минералах группы чевкинита (до 45 мас. \%), алланите (до22мас.\%),ортите(4-29мас.\%);Y-Nbоксидыявляютсяосновныминосителями Y(25-28мaс.\%)иНREЕ (9-11 мас. \%) (рис. 2).

Установленная последовательность кристаллизации минеральных парагенезисов указывает на процессы ремобилизации и фракционирования REE в ходе формирования апобазитовых метасоматитов:

1. Кристаллизация чевкинита-(Се), торита, фергусонита-(Y), циркона и монацита-(Се);

2. Замещение чевкинита-(Cе) ферриалланитом-(Се) под воздействием гидротермальных растворов: чевкинит-(Cе) $+\mathrm{Ca}+\mathrm{Al} \rightarrow$ ферриалланит-(Cе) $+\mathrm{LREE}+\mathrm{Fe}+\mathrm{Si}+\mathrm{Nb}+\mathrm{Ti}$;

3. Замещение ферриалланита-(Се) алланитом-(Се): ферриалланит-(Cе) $+\mathrm{Ca}+\mathrm{Al} \rightarrow$ алланит(Ce) + HREE + Fe;

4. Кристаллизация гадолинита-(Се) с последующим формированием по нему хинганита-(Cе) и высвобождением части REE и Fe;

5. Замещение ферриалланита-(Cе) минеральной ассоциацией ильменит + титанит+рутил со значительным высвобождением REE и $\mathrm{Si}$;

6. Кристаллизация кварца и REE-карбонатов. 
Последовательность кристаллизации минералов и их состав указывают на то, что формирование апобазитовых метасоматитов происходило из щелочных фторсодержащих флюидов при высокой активности $\mathrm{CO}_{2}, \mathrm{Si}, \mathrm{Ca}$ и $\mathrm{Al}$ на некоторых этапах. Значительная роль фтора во флюиде подчеркивается присутствием в метасоматитах флюорита, фторапатита и бастнезита-(Се). На высокую активность фтора также указывают значения отношения Y/Dy в самарските-(Y) - 14-16 (по [8]). Поскольку REE-карбонаты кристаллизуются, в основном, в виде наиболее поздних прожилков, $\mathrm{CO}_{2}$ является важным компонентом флюида на последних стадиях формирования метасоматитов. Текстурные взаимоотношения титанита, ильменита и рутила говорят о возможности прохождения реакций: ильменит $+\mathrm{CO}_{2}+\mathrm{REE}=$ рутил $+\mathrm{REE-карбонат}+$ магнетит и титанит $+\mathrm{CO}_{2}+\mathrm{REE} \rightarrow$ рутил $+\mathrm{REE}$-карбонат $+\mathrm{SiO}_{2}$ (по [11]); и, соответственно, относительно высокой $\mathrm{fCO}_{2}$.

Установленные минеральные ассоциации и особенности составов минералов позволяют выявить другие параметры флюида, в частности температуру и относительную фугитивность кислорода. Парагенезис кварца и эпидота позволяет предположить, что редкометальные руды месторождения испытали одну из последних стадий метасоматоза - кислотное выщелачивание. Несмотря на то, что эпидот кристаллизуется в широком температурном интервале $250-600^{\circ} \mathrm{C}$ [6], присутствие в породе безполевошпатового минерального парагенезиса кальцит-магнетит-эпидот предполагает низкие температуры, до $310^{\circ} \mathrm{C}$, и высокую $\mathrm{fO}_{2}$ (расчетные данные [1]).

Данные по составу редкометальных минералов свидетельствуют об изменении окислительных условий на разных стадиях формирования апобазитового метасоматита. Показано, что положительные Се аномалии в минералах указывают на высокие окислительные условия при их формировании $[3,7,10]$. В метасоматите положительные Се аномалии обнаружены в некоторых торитах, ферриалланите-(Се),гадолините-(Се),хинганите-(Се)иэшините-(Се), аотрицательные-всамарските(Y) и в некоторых торитах (рис. 2). Повышенное содержание $\mathrm{MnO}$ в ильмените (до 5.10 мас. \%) свидетельствовует о понижении $\mathrm{fO}_{2}$ в ходе его кристаллизации (по [4]). Более того, присутствие галенита в рутил-ильменит-титанитовых срастаниях и внутри измененного циркона указывает на значительную $\mathrm{fS}_{2}$ и восстановительные условия. Таким образом, в целом окислительный характер флюида в случае Ельозерского месторождения может изменяться на некоторых стадиях формирования метасоматита.

Кварцолиты Ровозерского проявления приурочены к пологим контактам щелочных гранитов Западнокейвского массива и располагаются как внутри гранитов, так и в гнейсах экзоконтактовых зон. Кварцолитовые тела весьма разнообразны по форме, размеру (от 0.5 до 1.5 м) и составу. Кварцолиты представляют собой неравномернозернистые такситовые породы, содержащие не менее 50 об. \% кварца и не более 10 об. \% полевых шпатов и в качестве второстепенных минералов - эгирин, арфведсонит, аннит, магнетит, ильменит, флюорит. Значительное количество флюорита и других F- или OH-содержащих минералов указывает на активное участие флюида при формировании кварцолитов. Редкометальная минерализация в кварцолитах достигает 20-30 об. \% и характеризуется разнообразным составом (более 10 минералов $\mathrm{Y}, \mathrm{Nb}, \mathrm{REE}, \mathrm{Zr}, \mathrm{Th}$ ). Распределение REE в кварцолитах сходно с таковым для апобазитовых метасоматитов (рис. 1), при этом некоторые образцы имеют даже обратный наклон в распределении REE, то есть породы также испытали гидротермальную переработку фторсодержащими растворами.

Типоморфным сквозным минералом редкометальной ассоциации в кварцолитах является циркон. К нему добавляются развитые резко неравномерно (от первых граммов до десятков килограммов на тонну породы) и не повсеместно - эшинит-(Y), чевкинит-(Се), фергусонит-(Y), фторбритолит-(Y), иттриалит-(Y), торит, монацит-(Се), ксенотим-(Y), бастнезит-(Се).

Фторбритолит-(Y) и иттриалит-(Y) являются главными носителями REE, их содержание в некоторых телах может достигать 10-15 об. \%. Распределение редкоземельных элементов во фторбритолите-(Y) (рис. 3 a) характеризуется синусоидальной формой с преобладанием HREЕ над LREE и ярко выраженными минимумами для Pr и Nd. Распределение редкоземельных элементов в иттриалите-(Y) (рис. 3 б) сходно с таковым для фторбритолита-(Y), отличаясь меньшим количеством наиболее легких REE. 


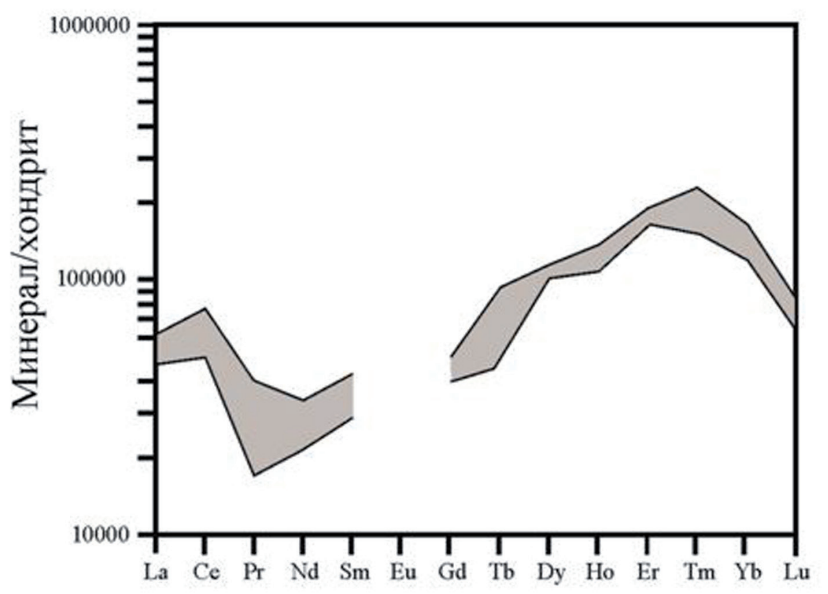

(a)

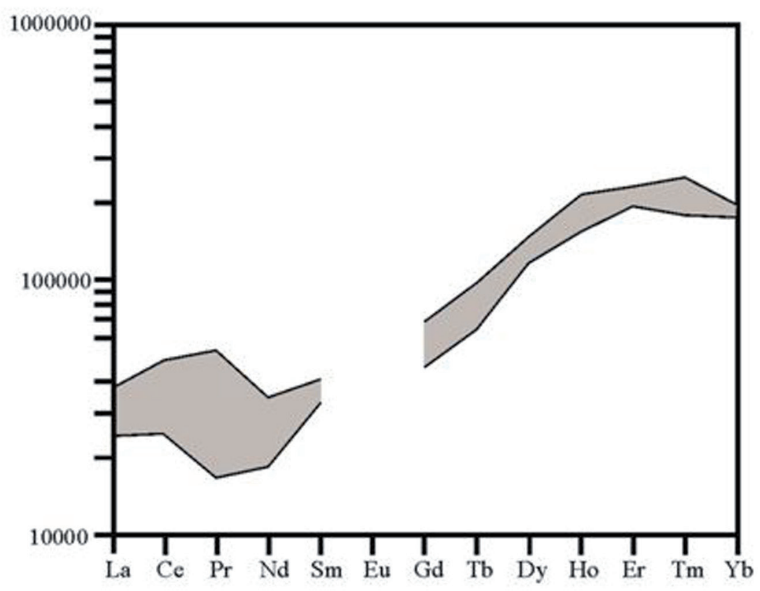

(б)

Рис. 3. Хондрит-нормализованное распределение REE во фторбритолите-(Y) (а) и иттриалите-(Y) (б) из кварцолитов Ровозерского проявления.

Ранее было показано, что отношения $\mathrm{Y} / \mathrm{Dy}$ и $\mathrm{La} / \mathrm{Nd}_{\mathrm{n}}$ в бритолитах являются показателями состава флюида [12]. Вариации Y/Dу во фторбритолите-(Y) и иттриалите-(Y) составляют 7-11 и 7-16, соответственно, и указывают на высокую активность фтора во флюиде. $\mathrm{La} / \mathrm{Nd}_{\mathrm{n}}$ изменяется в пределах 1.5-2.5 во фторбритолите-(Y) и 0.8-1.8 в иттриалите-(Y), что говорит об отсутствии $\mathrm{CO}_{2}$ во флюиде. При этом соотношение $\mathrm{H}_{2} \mathrm{O} / \mathrm{F}$ в среде кристаллизации иттриалита-(Y) значительно выше, чем для фторбритолита-(Y).

Работа выполнена при финансовой поддержке РФФИ (грант № 16-05-00427) и Госзадания (тема НИР 0231-2015-0009).

\section{Литература}

1. Кольцов А.Б. Гидротермальное минералообразование в термобароградиентных полях // Геохимия. 2010. 11. C. 1169-1184.

2. Минеев Д.А. Геохимия апогранитов и редкометальных метасоматитов северо-западного Тарбагатая. М.: Наука. 1968. 183 с.

3. Berger A., Gnos E., Janots E., Fernandez A., Giese J. Formation and composition of rhabdophane, bastnäsite and hydrated thorium minerals during alteration: implications for geochronology and low-temperature processes // Chem. Geol. 2008. 254. P. 238-248.

4. Cassidy K.F., Groves D.I., Binns R.A. Manganoan ilmenite formed during regional metamorphism of Archean mafic and ultramafic rocks from Western Australia // Can. Mineral. 1988. 26. P. 999-1012.

5. Charoy B.L., Raimbault L. Zr-, Th-, and REE-rich biotite differentiates in the A-type granite pluton of Suzhou (Eastern China): the key role of fluorine // J. Petrol. 1994. 35. P. 919-962.

6. Frey M., Capitani C., Liou J.G. A new petrogenetic grid for low-grade metabasites // J. Metamorphic Geol. 1991. 9. P. 497-509.

7. Gieré R., Sorensen S.S. Allanite and other REE-rich epidote-group minerals. In «Epidotes», A. Liebscher \& G. Franz, eds., Miner. Soc. Am., Rev. Mineral. Geochem. 2004. 56. P. 431-493.

8. Gramaccioli C.M., Diella V., Demartin F. The role of fluoride complexes in REE geochemistry and the importance of 4f electrons: some examples in minerals // Eur. J. Mineral. 1999. 11. P. 983-992.

9. Taylor R.P., Strong D.F., Fryer B.J. Volatile control of contrasting trace element distributions in peralkaline granitic and volcanic rocks // Contrib. Mineral. Petrol. 1981. 77. P. 267-271.

10. Uher P., Ondrejka M., Konečny P. Magmatic and postmagmatic Y-REE-Th phosphate, silicate and Nb-TaY-REE oxide minerals in A-type metagranite: an example from the Turčok massif, the Western Carpathians, Slovakia // Mineral. Mag. 2009. 73. P. 1009-1025.

11. Wang R.C., Wang D.Z., Zhao G.T., Lu J.J., Chen Xiao M., Xu S.J. Accessory mineral record of magma-fluid interaction in the Laoshan I- and A-type granitic complex, Eastern China // Phys. Chem. Earth. 2001. A26. P. 835-849.

12. Zozulya D., Lyalina L., Savchenko Ye. Britholite-group minerals as sensitive indicators of changing fluid composition during pegmatite formation: evidence from the Keivy alkaline province, Kola Peninsula, NW Russia // Mineralogy and Petrology. 2017. Vol. 111 (4). P. 511-522. 